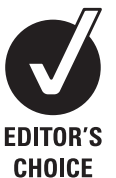

${ }^{1}$ Institute of Social Medicine, School of Medicine, University of Belgrade, Belgrade, Serbia ${ }^{2}$ Violence against Women research, Geneva, Switzerland ${ }^{3}$ Women Health Promotion Center, Belgrade, Serbia

\section{Correspondence to}

Dr Bosiljka Djikanovic, Institute of Social Medicine, School of Medicine, University of Belgrade, Serbia, Dr Subotica 8, 11000 Belgrade, Serbia; bosiljka_djikanovic@yahoo.com

Henrica A F M Jansen Epidemiologist, WHO Multi-country Study on Women's Health and Domestic Violence at the World Health Organization, Geneva, Switzerland, at the time this work was initiated

Accepted 30 July 2009

\title{
Factors associated with intimate partner violence against women in Serbia: a cross-sectional study
}

\author{
Bosiljka Djikanovic, ${ }^{1}$ Henrica A F M Jansen, ${ }^{2}$ Stanislava Otasevic ${ }^{3}$
}

ABSTRACT

Background This study aimed to identify factors associated with intimate partner violence against women living in Belgrade, Serbia.

Method A cross-sectional, population based household survey was conducted in Belgrade as part of the WHO Multi-country Study on Women's Health and Domestic Violence, using a standard questionnaire. Face-to-face interviews were conducted with 1456 women aged 15-49 years. Data used in this study were from a subset of 886 women who ever cohabited with their male intimate partners. The association between various factors at individual and relationship levels and reported physical or sexual partner violence, or both, was assessed by univariate and multivariate logistic regression analysis.

Results Multivariate logistic regression modelling revealed that partner violence was significantly associated with a number of factors relating to the male partner: daily alcohol consumption (AOR 4.25, 95\% Cl 1.78 to 10.11 ), having affairs (AOR $3.97,95 \% \mathrm{Cl} 1.62$ to 9.57), fighting with other men (AOR $3.62,95 \% \mathrm{Cl} 1.91$ to 6.88), his mother having experienced spousal abuse (AOR 2.71, 95\% Cl 1.40 to 5.23) and he himself being beaten as a child (AOR 3.14, 95\% Cl 1.48 to 6.63). Among the factors related to the women, only forced or unwanted first sexual intercourse was independently associated with exposure to partner violence (AOR 2.50, 95\% Cl 1.05 to 5.96).

Conclusion The majority of factors associated with intimate partner violence related to the male partner; in particular his childhood experiences of violence in his own family. Long-term violence prevention programmes should target boys growing up in families with domestic violence.

\section{INTRODUCTION}

Violence against women is a widespread phenomenon with consequences for women's physical and mental health. ${ }^{1-6}$ Violence against women most often happens in the context of relationships with male intimate partners. ${ }^{7}$ The prevalence of physical or sexual intimate partner violence (IPV), or both, varies between 15 and $71 \%$ in different cultures. ${ }^{2}$ IPV is violence based on gender inequality, and is frequently considered as a form of 'gender-based violence'. ${ }^{8}$ There is a general consensus that no single cause adequately accounts for IPV. To understand the interplay of factors that combine to cause IPV, researchers are increasingly using an ecological framework in which risk factors at individual, relationship, community and societal levels are represented as nested circles. ${ }^{29}$ Studies worldwide have attempted to identify factors associated with IPV. ${ }^{10-17}$ Alcohol consumption has frequently been identified as being associated with IPV due to its association with arguing and conflicts, ${ }^{13}$ or because of the link with unemployment, ${ }^{14}$ although there is insufficient evidence to confirm alcohol consumption as an independent risk factor for violence ${ }^{15}$ and it could be part of another underlying problem. Recent or temporary unemployment of the male partner and his lower education level, especially in relation to his female partner, have been shown to be associated with IPV. ${ }^{11}{ }^{16}$ Further, some studies showed that exposure to domestic violence in his childhood, and witnessing his mother being beaten by her spouse, were associated with violent behaviour towards his female partner in adulthood. ${ }^{17}$ Some studies also found that the partner's infidelity was associated with violent behaviour towards his female intimate partner. $^{18} 19$

There is less evidence for associations between factors related to women and their experience of being abused, although early studies looked at this. ${ }^{20}$ Reviews on the state of knowledge highlight the role of marital conflicts and lower socioeconomic status of household of the women, ${ }^{21} 22$ which are actually characteristics of the relationship. Furthermore, a study on very poor women showed that having been sexually abused as a child was associated with violence in adulthood. ${ }^{23}$ Other factors include inadequate emotional support and social network in adulthood, ${ }^{23-26}$ and poor selfesteem, ${ }^{23} 27$ although the authors acknowledged that it was difficult to assess whether this situation preceded violence or developed as a result of repeated exposure to violence.

The context for violence - the outer circle of the ecological framework - also plays a role. ${ }^{28} 29$ At the society level, perceptions of gender roles and of the acceptability of domestic violence vary between countries and communities. These are related to tradition, culture and socioeconomic development and have been shown to be related to IPV. ${ }^{30}$ Some studies have shown that the process of women's empowerment initially put them at a greater risk of experiencing male IPV, due to the changes in traditionally perceived gender roles. ${ }^{31} 32$

For the present study it is noteworthy that the Serbian society has been through political and economic turmoil over the past 20 years. The disintegration of the former Yugoslavia was followed by wars in the 1990s. The availability of weapons increased, as did other crimes and interpersonal violence. The years after 2000 brought stability, but also the painful process of transition from communism to market-oriented economies, followed by the advancement of women's role in 
society. ${ }^{33}$ This context is relevant to understanding the situation of Serbia, although in this study the aim was not to establish the impact of the situation on the experience of violence, because this was the first time that population-based data on violence against women had been collected.

Nevertheless, the data collected enabled exploration of the inner circles of the ecological framework and the aim of this analysis was to investigate selected individual and relationship factors associated with IPV in a representative sample of women aged 15-49 years living in Belgrade, the capital of Serbia.

\section{METHOD}

\section{Study sample}

A cross-sectional, population-based survey was conducted in Belgrade, Serbia, in 2003, as a part of the WHO Multi-country Study on Women's Health and Domestic Violence against Women, implemented by the Autonomous Women Centre (a women's non-governmental organisation from Belgrade). ${ }^{7} 34$ The method, sampling strategy and ethical considerations have been described elsewhere. ${ }^{75}$ The household response rate was $59.8 \%$, whereas the individual response rate was $88.9 \%$.

The instrument used in the survey measured exposure to physical or sexual violence by an intimate partner by asking about specific behavioural acts, which is an approach that has been shown to encourage greater disclosure of violence. ${ }^{7} 36$ Lifetime experience of IPV was considered to be present when a woman answered yes to having experienced at least one of six acts of physical violence or one of the three acts of sexual violence (box 1). ${ }^{37}$ The Cronbach $\alpha$ value for internal consistency for the nine items included in the measure for IPV was 0.81 .

Interviews were completed with 1456 women aged 15-49 years. Of these women 988 were ever married and/or had been living together with an intimate partner (further referred to as cohabited with intimate partner). Seven-hundred and twentynine women $(73.8 \%)$ did not report partner violence, whereas 259 women (26.2\%) reported physical and/or sexual violence by

Box 1 Questions related to exposure to physical and sexual violence, used in the questionnaire of the WHO Multi-country Study on Women's Health and Domestic Violence

Physical violence

Has your current husband/partner, or any other partner ever...

a. Slapped you or thrown something at you that could hurt you?

b. Pushed or shoved you or pulled your hair?

c. Hit you with his fist or with something else that could hurt you?

d. Kicked, dragged or beaten you up?

e. Choked or burnt you on purpose?

f. Threatened to use or actually used a gun, knife or other weapon against you?

Sexual violence

a. Were you ever physically forced to have sexual intercourse when you did not want to?

b. Did you ever have sexual intercourse you did not want because you were afraid of what he might do?

c. Did he ever force you to do something sexual that you found degrading or humiliating? a partner at a certain point in their life (figure 1). For this study, among the women who reported partner violence, only those women whose current or most recent partner was violent were included in the group that was exposed to violence, because data on partner characteristics were collected for the current or most recent partner only. Thus, the risk factor analysis used data from 886 women and their partners.

\section{Statistical analysis}

The analysis focused on selected potential risk factors related to the woman, her partner and their relationship, based on the conceptual model (the ecological framework) and published findings on risk factors. Descriptive cross-tabulations were done for each of these potential risk factors and the lifetime experience of physical and/or sexual violence, with the risk factors as the independent variables and lifetime IPV as the dependent variable. $^{38}$ Lifetime, and not current IPV (past 12 months), was selected as the dependent variable because the prevalence of current IPV in Belgrade was only 3.7\%, and low numbers in the exposed group would reduce the power of the analysis. Moreover, other studies have shown that risk factors correlate in similar ways with current and lifetime IPV except for age, with young age, in most contexts, being a predictor for increased current violence, but generally not for lifetime violence. ${ }^{23}$

The factors related to women that have been considered were: demographic data (age and education); women's informal social support network (proximity of members of family of birth, frequency of communicating with family of birth and counting on their support); experience of childhood sexual abuse before age 15 years; experience of physical and sexual violence perpetrated by non-partners; whether first sexual intercourse was wanted or coerced; and her mother's experience of partner violence.

The following factors related to partners were considered in addition to demographic data: alcohol consumption, drug consumption, fighting with other men, having parallel relationships with other women (infidelity), his mother's experience of partner violence and being beaten as a child.

Relationship characteristics included household's socioeconomic status, which was classified as belonging to one of three socioeconomic status groups that were constructed using principal component analysis; ${ }^{39}$ whether the couple lived with his or her family of birth, and difference in education between partners.

Univariate and multivariate logistic regression analyses were performed to assess the association between dependent and independent variables. Univariate ORs were estimated from the regression coefficients. A two-tailed probability value of 0.10 or less was considered significant. The independent variables, which, in univariate logistic regression analysis, showed significant association with partner violence were subsequently included in a multivariate logistic regression model. Also, age was included in the model, for control purposes. For this final model, a two-tailed probability value of 0.05 or less was considered significant. The fit of the logistic regression models was tested by likelihood ratio and the Hoshmer-Lameshow goodness-of-fit test. All analyses were performed with the Statistical Package for the Social Sciences, SPSS, version 15.0 (SPSS Inc).

\section{RESULTS}

The descriptive analysis of IPV according to characteristics of the respondent (woman), her partner and the relationship, along with results of the univariate logistic regression that was used to 
Figure 1 Numbers of women in the survey according to their reported partnership status and their experience of partner violence. The shaded boxes indicate the subset used for the analysis in this study.

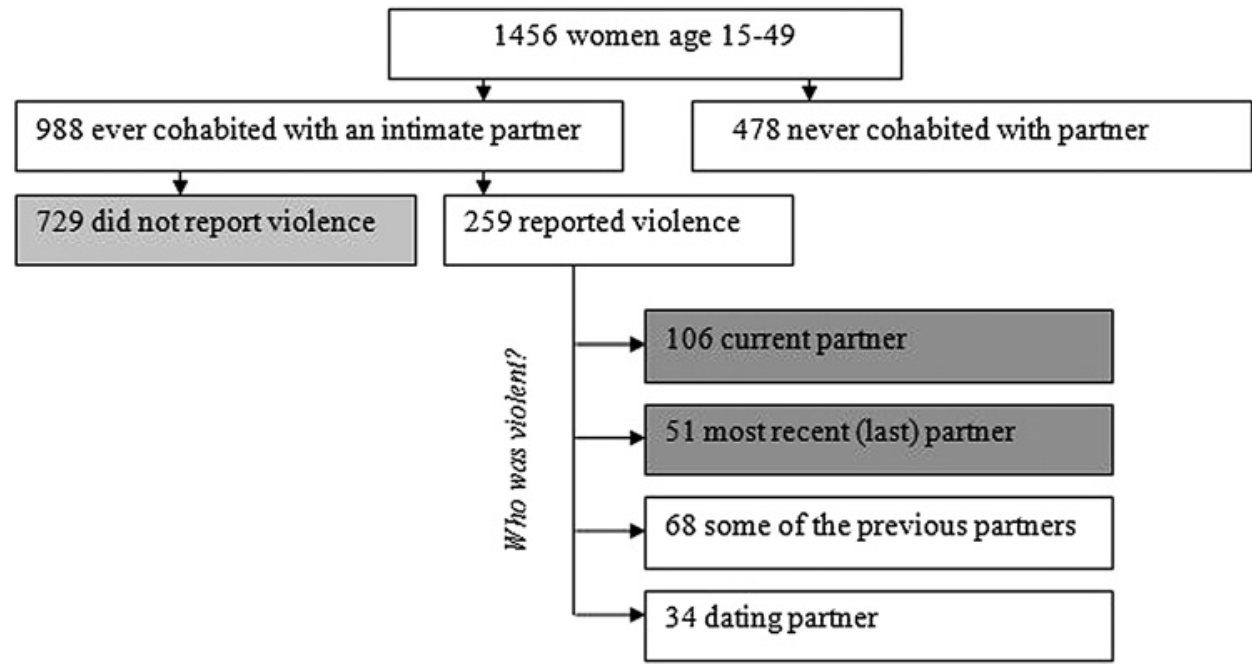

explore these variables as potential risk or protective factors for violence, are given in tables 1,2 , and 3 respectively.

Table 1 shows that women's age was not significantly associated with IPV, whereas women who had had only primary or secondary education were significantly more likely to have experienced IPV than women with higher education. Variables related to existence and functionality of the social support network of women, expressed through proximity of their family of birth and counting on family members for support, were not associated with violence; however, low frequency of talking with family members (less than weekly) was significantly associated with IPV (OR 2.37).

Table 1 Lifetime experience of physical or sexual partner violence, among women who ever cohabited, by women's characteristics: prevalence and univariate logistics regression analysis*

\begin{tabular}{|c|c|c|c|c|}
\hline Women's characteristics & $\begin{array}{l}\text { Total number } \\
\text { of women }\end{array}$ & $\begin{array}{l}\text { Experienced physical } \\
\text { or sexual violence) no. (\%) }\end{array}$ & OR (95\% Cl) & p Value \\
\hline \multicolumn{5}{|l|}{ Age group (years) } \\
\hline $15-24$ & 61 & $14(22.9)$ & $1.32(0.70$ to 2.48$)$ & 0.391 \\
\hline $35-49$ & 570 & $105(20.7)$ & 1.00 & \\
\hline \multicolumn{5}{|l|}{ Education } \\
\hline Primary education & 20 & $6(30.0)$ & $2.70(1.00$ to 7.23$)$ & 0.050 \\
\hline \multicolumn{5}{|l|}{ Proximity of her family of birth } \\
\hline Within visiting distance & 607 & $102(16.8)$ & 1.00 & \\
\hline Not living near by & 190 & $36(18.9)$ & $1.16(0.76$ to 1.76$)$ & 0.492 \\
\hline Living with her family of birth & 87 & $19(21.8)$ & 1.38 (0.78 to 2.40$)$ & 0.253 \\
\hline \multicolumn{5}{|c|}{ Frequency of communicating with her family members } \\
\hline Min. once a week & 726 & $117(16.1)$ & 1.00 & \\
\hline \multicolumn{5}{|l|}{ Reported child sexual abuse before age 15} \\
\hline No & 875 & $153(17.5)$ & 1.00 & \\
\hline Yes & 11 & $4(36.4)$ & $2.68(0.78$ to 9.33$)$ & 0.122 \\
\hline \multicolumn{5}{|l|}{ Experience of physical violence by non-partners } \\
\hline No & 810 & $130(16.1)$ & 1.00 & \\
\hline Yes & 76 & $27(35.5)$ & $2.88(1.73$ to 4.78$)$ & $<0.000$ \\
\hline \multicolumn{5}{|l|}{ Experience of sexual violence by non-partners } \\
\hline No & 864 & $148(17.1)$ & 1.00 & \\
\hline Yes & 22 & $9(40.9)$ & 3.35 (1.41 to 7.98$)$ & 0.006 \\
\hline \multicolumn{5}{|l|}{ Nature of the first sexual intercourse } \\
\hline Wanted & 833 & $136(16.3)$ & 1.00 & \\
\hline
\end{tabular}

*The ORs express the odds for experiencing partner violence for each subcategory compared with a baseline category (in most cases the category with most counts). 
Table 2 Lifetime experience of physical or sexual partner violence, among women who ever cohabited, by their partner's characteristics: prevalence and univariate logistics regression analysis

\begin{tabular}{|c|c|c|c|c|}
\hline Partner's characteristics & $\begin{array}{l}\text { Total number } \\
\text { of women }\end{array}$ & $\begin{array}{l}\text { Experienced physical } \\
\text { or sexual violence no. (\%) }\end{array}$ & OR $(95 \% \mathrm{CI})$ & p Value \\
\hline \multicolumn{5}{|l|}{ Age group (years) } \\
\hline $20-34$ & 221 & $33(14.9)$ & 0.74 (0.42 to 1.28$)$ & 0.283 \\
\hline $35-49$ & 511 & $93(18.2)$ & $0.94(0.83$ to 1.05$)$ & 0.283 \\
\hline $50-64$ & 151 & $29(19.2)$ & 1.00 & \\
\hline \multicolumn{5}{|l|}{ Education } \\
\hline Primary education & 19 & $5(26.3)$ & $2.53(0.87$ to 7.33$)$ & 0.086 \\
\hline Secondary education & 452 & $100(22.1)$ & $2.02(1.34$ to 2.91$)$ & $<0.000$ \\
\hline Higher education & 413 & $51(12.3)$ & 1.00 & \\
\hline \multicolumn{5}{|l|}{ Employment status } \\
\hline Working & 758 & $133(17.5)$ & 1.00 & \\
\hline Unemployed & 86 & $18(20.9)$ & 1.24 (0.71 to 2.16$)$ & 0.446 \\
\hline Retired & 26 & $2(7.7)$ & $0.39(0.09$ to 1.67$)$ & 0.202 \\
\hline Student & 9 & $1(11.1)$ & $0.58(0.07$ to 4.74$)$ & 0.617 \\
\hline \multicolumn{5}{|l|}{ Alcohol consumption } \\
\hline Never & 244 & $31(12.7)$ & 1.00 & \\
\hline Less than monthly & 256 & $37(14.5)$ & 1.61 (0.69 to 1.94$)$ & 0.569 \\
\hline Up to three times a month & 157 & $25(15.9)$ & 1.30 (0.74 to 2.30$)$ & 0.365 \\
\hline Once or twice a week & 141 & $29(20.6)$ & $1.78(1.02$ to 3.10$)$ & 0.042 \\
\hline Almost every day & 83 & $33(39.8)$ & 4.53 (2.54 to 8.09$)$ & $<0.000$ \\
\hline \multicolumn{5}{|l|}{ Drug consumption } \\
\hline Never & 866 & $147(17.0)$ & 1.00 & \\
\hline Sometimes/often & 8 & $6(0.75)$ & 14.67 (2.93 to 73.41$)$ & 0.001 \\
\hline \multicolumn{5}{|l|}{ Fighting with other men } \\
\hline No & 747 & $98(13.1)$ & 1.00 & \\
\hline Yes & 115 & $48(41.7)$ & 4.74 (3.09 to 7.27$)$ & $<0.000$ \\
\hline Do not know & 22 & $9(40.9)$ & $4.58(1.91$ to 11.01$)$ & 0.001 \\
\hline \multicolumn{5}{|c|}{ Having parallel relationship with other women (infidelity) } \\
\hline No & 742 & $97(13.1)$ & 1.00 & \\
\hline Yes & 51 & $28(54.9)$ & 8.09 (4.48 to 14.62$)$ & $<0.000$ \\
\hline May have, do not know & 91 & $30(33.0)$ & 3.27 (2.01 to 5.32$)$ & $<0.000$ \\
\hline \multicolumn{5}{|c|}{ Partner's mother was beaten by mother's partner } \\
\hline No & 597 & $69(11.6)$ & 1.00 & \\
\hline Yes & 117 & $45(38.5)$ & 4.78 (3.05 to 7.49$)$ & $<0.000$ \\
\hline Do not know & 161 & $40(24.8)$ & $2.53(1.63$ to 3.91$)$ & $<0.000$ \\
\hline \multicolumn{5}{|c|}{ Partner was beaten as a child, by family member } \\
\hline No & 698 & $83(11.9)$ & 1.00 & \\
\hline Yes & 79 & $39(49.4)$ & 7.22 (4.39 to 11.88$)$ & $<0.000$ \\
\hline Do not know & 107 & $34(31.8)$ & $3.45(2.16$ to 5.50$)$ & $<0.000$ \\
\hline
\end{tabular}

Exposure to violence by people other than the partner was also significantly associated with IPV. Women who had ever experienced either physical or sexual violence by perpetrators other than partners had odds of 2.88 , and 3.35 , respectively, of experiencing IPV. Women whose first sexual intercourse was unwanted (including forced sex) had an odds of 3.84 of experiencing IPV compared to women whose first intercourse was not coerced. Further, having a mother who was beaten by her partner was also significantly associated with IPV (OR 2.75).

Table 2 presents the associations between each of the partner's characteristics and the respondent's experience of IPV. The partner's age and employment status were not significantly associated with IPV. Compared to partners with higher education, the odds for IPV doubled when the partner had only secondary education, and the odds were even higher when the partner's educational level was below secondary education. Frequent alcohol use strongly increased the odds for IPV compared to no alcohol use: the OR for alcohol consumption once or twice a week was 1.78 and for daily use 4.53. Although the number of women who reported their partners used drugs was very small, drug use was very strongly associated with IPV (OR 14.67).
Aggressive behaviour towards other men was significantly associated with IPV (OR 4.74), and when women did not know their partner's history regarding aggressive behaviour towards others, there was a strikingly similar association with IPV (OR 4.58). Having parallel (concurrent) relationships with other women was also strongly and significantly associated with IPV (OR 8.09). Also here, the lack of women's knowledge of their partner's infidelity, or just being suspicious that he was having affairs (answer: 'May have, I do not know') was associated with IPV.

Furthermore, having a partner whose mother was beaten by her partner was strongly associated with IPV (OR 4.78). When a woman replied she did not know if her mother-in-law had been beaten, there was also an association in the same direction with the woman's experience of IPV (OR 2.53). The partner's experience of having been beaten as a child was also significantly associated with IPV (OR 7.22).

The associations between characteristics of the couple's relationship and the woman's experience with IPV are presented in table 3. A household's low socioeconomic status, in comparison to high, was significantly associated with IPV (OR 2.20). 
Table 3 Lifetime experience of physical or sexual partner violence, among women who ever cohabited, by characteristics of their couple's relationship: prevalence and univariate logistics regression analysis

\begin{tabular}{|c|c|c|c|c|}
\hline Relationship's characteristics & $\begin{array}{l}\text { Total number } \\
\text { of women }\end{array}$ & $\begin{array}{l}\text { Experienced physical } \\
\text { or sexual violence no. (\%) }\end{array}$ & OR $(95 \% \mathrm{Cl})$ & p Value \\
\hline \multicolumn{5}{|l|}{ Socioeconomic status } \\
\hline Low & 163 & $43(26.4)$ & $2.20(1.37$ to 3.55$)$ & 0.001 \\
\hline Medium & 347 & $60(17.3)$ & $1.28(0.84$ to 1.97$)$ & 0.253 \\
\hline High & 300 & $42(14.0)$ & 1.00 & \\
\hline \multicolumn{5}{|l|}{ Cohabitation with partner's family } \\
\hline No & 610 & $97(15.9)$ & 1.00 & \\
\hline Yes & 272 & $59(21.7)$ & $1.46(1.02$ to 2.10$)$ & 0.038 \\
\hline \multicolumn{5}{|c|}{ Cohabitation with woman's family of birth } \\
\hline No & 753 & $127(16.7)$ & 1.00 & \\
\hline Yes & 128 & $28(21.9)$ & $1.38(0.87$ to 2.18$)$ & 0.170 \\
\hline \multicolumn{5}{|l|}{ Discrepancy in education } \\
\hline Equal & 632 & $106(16.8)$ & 1.00 & \\
\hline Partner more educated & 103 & $17(16.5)$ & $0.98(0.56$ to 1.71$)$ & 0.946 \\
\hline Woman more educated & 137 & $28(20.4)$ & $1.27(0.80$ to 2.03$)$ & 0.306 \\
\hline
\end{tabular}

Further, cohabitation with the partner's family was associated with IPV, whereas cohabitation with the woman's family of birth was not. Discrepancy between partners and respondents in level of education was not significantly associated with IPV.

After putting independent variables with significance level ( $p$ ) of equal to or less than 0.10 at the univariate level into a multivariate logistic regression model (table 4), only one variable of those related to women remained significant: having experienced unwanted or forced first sexual intercourse (AOR 2.50, $95 \%$ CI 1.05 to 5.96). None of the relationship factors remained significantly associated with violence, whereas the rest of the variables that remained significantly associated with IPV, net of all the others, all came from the male partner's side.

These characteristics include: lower educational level secondary education in comparison to high education (AOR $2.25,95 \%$ CI 1.25 to 4.07 ), daily alcohol consumption (AOR $4.25,95 \%$ CI 1.78 to 10.11 ), fighting with other men (AOR 3.62, $95 \%$ CI 1.91 to 6.88), having affairs with other women (AOR $3.97,95 \%$ CI 1.62 to 9.57 ), as well as factors or variables related with his childhood family background, such as that his mother was beaten by her partner (AOR 2.71, 95\% CI 1.40 to 5.23), and that he himself was beaten as a child by a family member (AOR $3.14,95 \%$ CI 1.48 to 6.63$)$.

\section{DISCUSSION}

This study indicates that the majority of factors associated with IPV against women are factors related to the male partner: his daily alcohol consumption, infidelity, being less educated and his personal experiences of violence in childhood. On the woman's side, the only independently remaining predictor of IPV was having experienced forced or unwanted first sexual intercourse. These results shed a light on the complex factors that play a role in IPV: individual factors of the woman and those of her partner, current factors and factors related to events early in their lives.

Heise's ecological framework ${ }^{9}$ for understanding IPV, adapted with an additional 'partner circle', overlapping with the 'individual circle' to symbolize a couple's relationship (C Watts personal communication), is presented in figure 2. Although one limitation of the present analysis is that it has only been possible to look at potential risk factors at the individual and relationship levels, the analysis nevertheless revealed strong and consistent patterns, in particular for factors related to the woman's partner. Those factors that remained significant in the final model have been inserted into the framework in figure 2 .
A major strength of these findings is that the data come from a randomised, population-based sample of women living in Belgrade. This was the first study in Serbia that aimed to comprehensively assess prevalence of violence against women and related factors. ${ }^{40}$ Another strength is the robust methodology used (WHO Multi-country Study on Violence Against Women), which assures that findings are of high quality and internationally comparable with many other sites worldwide where the same method was and is being used. ${ }^{7}$

Another limitation is the relatively low household response rate $(59.8 \%)$, compared to other countries where the same methodology was applied, ${ }^{7}$ even if this response rate was better than usually obtained in Belgrade (Dragisa Bjeloglav, Strategic Marketing, survey company in Belgrade, personal communication, 2003). The response rate could have been affected by the assassination of the Serbian Prime Minister Zoran Djindjic at the time that the field work was starting, and the confusion and distrust that was produced by the emergency situation. Nevertheless, once collaboration was achieved at household level, most women completed the interview (and the individual response rate was $88.9 \%$ ). Women who refused, were absent or did not complete the interview had a median age of 34 years, compared to 32 years for women who completed the interview.

Another limitation is that the results on victims pertain to a subset who were victimised by the most recent or current partner and the characteristics of these women and their partner may be different from those of the victims excluded from the study. Although no statements can be made on the partner characteristics, as data on these were not collected for former partners, the excluded victims were compared with the included victims for women and relationship characteristics and no statistically significant differences were observed. Yet another limitation of the study is that it is based on self-report by women only and may be biased when it comes to reporting on partner's characteristics.

It has been mentioned that studies on violence against women are usually biased towards under-reporting of violence, due to the taboos and stigma surrounding the topic, whereas an overestimation of the effect is unlikely, due to the nature of the measured experience. ${ }^{8} 41$ The methodology developed for the WHO study, including the special training of interviewers, was designed to maximise disclosure of violence. ${ }^{42}$

Because it was a cross-sectional study there are limitations for establishing causal relationships, although the risk factors 
Table 4 Multivariate logistic regression modelling for factors associated with experiencing intimate partner violence

\begin{tabular}{|c|c|c|}
\hline Variables & AOR (95\% CI) & p Value \\
\hline \multicolumn{3}{|l|}{ Women's characteristics } \\
\hline \multicolumn{3}{|l|}{ Age group (years) } \\
\hline $15-24$ & $1.05(0.36$ to 3.01$)$ & 0.924 \\
\hline $25-34$ & $0.77(0.27$ to 2.14$)$ & 0.550 \\
\hline $35-49$ & 1.00 & \\
\hline \multicolumn{3}{|l|}{ Education } \\
\hline Primary education & $0.88(0.15$ to 5.12$)$ & 0.891 \\
\hline Secondary education & $0.72(0.40$ to 1.30$)$ & 0.281 \\
\hline Higher education & 1.00 & \\
\hline \multicolumn{3}{|c|}{ Frequency of talking with her family members } \\
\hline Min. once a week & 1.00 & \\
\hline Less than weekly & $1.68(0.78$ to 3.61$)$ & 0.182 \\
\hline \multicolumn{3}{|c|}{ Experience of physical violence by non-partners } \\
\hline No & 1.00 & \\
\hline Yes & $1.43(0.63$ to 3.21$)$ & 0.387 \\
\hline \multicolumn{3}{|c|}{ Experience of sexual violence by non-partners } \\
\hline No & 1.00 & \\
\hline Yes & $3.36(0.85$ to 13.31$)$ & 0.084 \\
\hline \multicolumn{3}{|l|}{ Nature of first sexual experience } \\
\hline Wanted & 1.00 & \\
\hline $\begin{array}{l}\text { Unwanted but happened (incl. forced } \\
\text { sex) }\end{array}$ & $2.50(1.05$ to 5.96$)$ & 0.037 \\
\hline \multicolumn{3}{|c|}{ Woman's mother was beaten by mother's partner } \\
\hline No & 1.00 & \\
\hline Yes & $1.50(0.81$ to 2.77$)$ & 0.188 \\
\hline \multicolumn{3}{|l|}{ Relationship's characteristics } \\
\hline \multicolumn{3}{|l|}{ Socioeconomic status (SES) } \\
\hline Low & $1.61(0.81$ to 3.20$)$ & 0.172 \\
\hline Medium & $1.34(0.75$ to 2.40$)$ & 0.321 \\
\hline High & 1.00 & \\
\hline \multicolumn{3}{|l|}{ Cohabitation with partner's family } \\
\hline No & 1.00 & \\
\hline Yes & $1.63(0.97$ to 2.72$)$ & 0.063 \\
\hline \multicolumn{3}{|l|}{ Partner's characteristics } \\
\hline \multicolumn{3}{|l|}{ Education } \\
\hline Primary education & $2.04(0.33$ to 12.69$)$ & 0.441 \\
\hline Secondary education & $2.25(1.25$ to 4.07$)$ & 0.007 \\
\hline Higher education & 1.00 & \\
\hline \multicolumn{3}{|l|}{ Alcohol consumption } \\
\hline Never & 1.00 & \\
\hline Less than monthly & $2.08(1.02$ to 4.26$)$ & 0.044 \\
\hline Up to three times a month & $1.40(0.62$ to 3.17$)$ & 0.414 \\
\hline Once or twice a week & $2.00(0.90$ to 4.42$)$ & 0.086 \\
\hline Almost every day & $4.25(1.78$ to 10.11$)$ & 0.001 \\
\hline \multicolumn{3}{|l|}{ Drug consumption } \\
\hline Never & 1.00 & \\
\hline Sometimes/often & $4.40(0.32$ to 59.74$)$ & 0.265 \\
\hline \multicolumn{3}{|l|}{ Fighting with other men } \\
\hline No & 1.00 & \\
\hline Yes & $3.62(1.91$ to 6.88$)$ & $<0.000$ \\
\hline Do not know & $4.05(1.23$ to 13.40$)$ & 0.021 \\
\hline Having parallel relationship with other w & & \\
\hline No & 1.00 & \\
\hline Yes & 3.97 (1.62 to 9.57$)$ & 0.003 \\
\hline May have, she does not know & $1.82(0.85$ to 3.89$)$ & 0.120 \\
\hline Partner's mother was beaten by mother' & & \\
\hline No & 1.00 & \\
\hline Yes & $2.71(1.40$ to 5.23$)$ & 0.003 \\
\hline Do not know & $2.02(1.05$ to 3.89$)$ & 0.034 \\
\hline Partner was beaten as a child, by family & & \\
\hline No & 1.00 & \\
\hline Yes & $3.14(1.48$ to 6.63$)$ & 0.003 \\
\hline Do not know & $2.42(1.16$ to 5.05$)$ & 0.018 \\
\hline
\end{tabular}

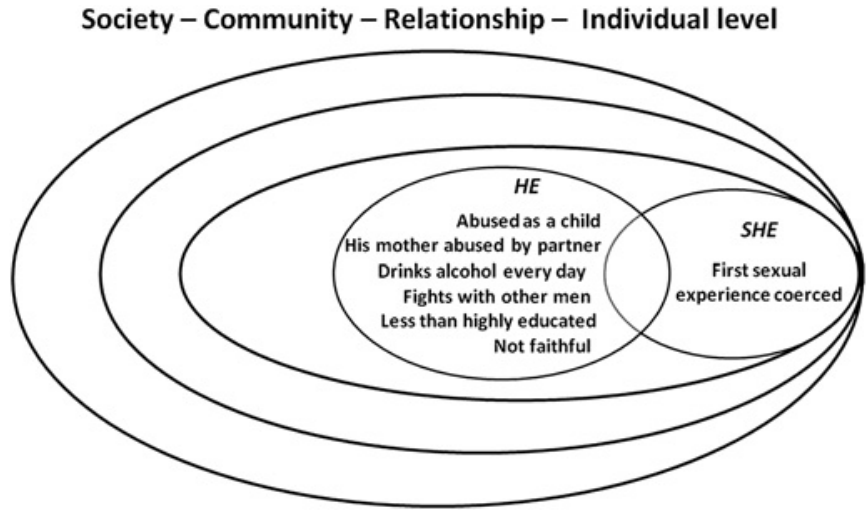

Figure 2 Ecological framework showing factors significantly associated with intimate partner violence in Serbia (adapted from Heise et $a l^{9}$ ).

related to the partner's childhood that remained significant in the final model clearly dated from before the relationship.

In comparison to the original core questionnaire, the questionnaire used in Serbia missed sections related to financial independence of women, and details on the respondent's children. These sections were omitted due to the limited resources for the study, and were at the time not considered crucial for getting an overall picture of exposure to violence. However, it is now believed that for understanding the risk factors associated with IPV, it would have been beneficial to have these data as well. The relationship between women's financial autonomy and exposure to violence has been inconsistent in findings from studies conducted worldwide: in some places, financial autonomy increases women's risk for being beaten by her partner, ${ }^{32}$ whereas in others, in developed countries, it protects them as it may enable women to leave an abusive relationship. $^{32} 43$

Detailed risk factor analysis to identify context-specific factors related to IPV has not yet been conducted for most sites in the WHO Multi-country Study, with the exception of Bangladesh ${ }^{32}$ and Brazil. ${ }^{44}$ Also for Vietnam, where a modified version of the WHO questionnaire has been used, similar analysis has been done. ${ }^{45}$ The results of these studies have in common that women's characteristics, such as low level of education, sexual abuse during childhood or having a mother who was beaten by her partner, were shown to be significantly associated with IPV. In the present analysis these variables were significantly associated with IPV only in the univariate logistic regression model, whereas they lost significance in the final model. In comparison to these other studies, which used the same methods, the present results emphasised the importance of factors coming from the partner's side.

The findings on risk factors for violence (as summarised in figure 2) are consistent with results from previous studies, in other cultures, where men's exposure to family violence in childhood predicted violent behaviour towards women later in life. ${ }^{13} 17$ Another commonly identified factor is alcohol abuse: ${ }^{11}{ }^{14-16}$ the present results showed that, in particular, daily consumption of alcohol was strongly associated with IPV.

The findings also indicate that when the first sexual experience was coerced or forced, a woman is more likely to have experienced IPV. This could be attributed to factors such as women's learnt submissive behaviour or difficulties in asserting themselves in an environment that is not supportive and where gender norms are traditional. This could also relate to the finding 
in other studies that victimised women are more likely to be victimised again. ${ }^{21}$

A striking finding from the present study is that partners' infidelity (seeing one or more women concurrently while being with the respondent) was correlated with IPV. This finding might help explain how partner violence jeopardises women's reproductive health. Having concurrent partners may lead to an increased risk for sexually transmitted infections, and, together with violence, contributes to psychological burden, low selfesteem, and feelings of embarrassment and humiliation. ${ }^{46}$

Another interesting finding is that respondents who reported that their partner fought with other men, or that their partner had been beaten as a child, had quite similar odds of experiencing IPV compared to women who stated that they did not know if this was the case for their partner. If respondents did not know whether their partner was faithful or not, the odds for IPV were also increased, although in the final model it was no longer statistically significant. This shows that 'don't know' answers cannot be ignored. These 'don't know' answers could perhaps be explained by the respondents' desire to avoid 'losing face' or being too embarrassed to confirm (eg, in case of unfaithfulness) in front of interviewers, whereas in other situations, it might be simply that they do not know these facts, as a result of poor communication between partners. The latter would support the finding of others that poor communication is correlated with violence. ${ }^{47}$

The importance of risk factors analysis for IPV lies in the potential to use the findings for focusing violence prevention activities on particular aspects that have been shown to be associated with violent behaviour. This study adds to the body of evidence that supports the recommendation that special attention should be given to efforts to 'break the chain of violence', as violence is behaviour that is learnt, often in childhood. Raising women's awareness of factors that might predict violence is also important.

\section{What is already known on this subject}

Studies in other settings have shown that a woman's experience with intimate partner violence is associated with:

- her partner's alcohol consumption;

- her partner being exposed to family violence as a child;

her partner's aggressive behaviour towards other men.

\section{What this study adds}

- This is the first time comprehensive data have been available on prevalence of and risk factors for intimated partner violence (IPV) in Serbia.

- The forced or coerced nature of a woman's first sexual experience predicts her exposure to IPV later in life. Although this is a new finding, it is in line with other findings on revictimisation of already victimised women.

- Characteristics of the male partner are confirmed to be more important risk factors for IPV than characteristics of the woman.

- Male partner's infidelity is confirmed to be associated with violent behaviour towards his regular female partner.

\section{CONCLUSION}

The majority of factors that were significantly associated with physical or sexual IPV are related to the male partner. His childhood experiences with violence in his own family stood out as an important factor. Long-term violence prevention activities have to consider this and target interventions at boys growing up in families with domestic violence to break the cycle of violence.

Acknowledgements This study was part of the WHO Multi-country Study on Women's Health and Domestic Violence conducted in ten countries worldwide. We would like to thank all the women who agreed to be interviewed, as well as the field staff (interviewers and supervisors) for the field work. The survey in Serbia was implemented by the Autonomous Women Centre and funded by Trocaire, Ireland. The principal investigators were Dr Stanislava Otasevic, Dr Viktorija Cucic and Dr Silvia Koso. We would also like to acknowledge the reviewers for their excellent comments and suggestions for the improvement of this paper and the WHO for clearing this paper for publication.

\section{Competing interests None.}

\section{Patient consent Obtained.}

Ethics approval Permission for the WHO Multi-country Study was obtained from the WHO Secretariat Committee for Research in Human Subjects. The study in Serbia strictly adhered to WHO's ethical and safety recommendations for research on Domestic Violence against Women.

Contributors All authors were involved in the implementation of the survey (SO was principal investigator, managed the project overall, supported field staff, and led on report writing for the 2005 report with initial results; HJ was technical advisor to the study, trained field staff and data processing staff, and contributed to data analysis for the 2005 report with initial results; BD was interviewer); BD and HJ conceived the study presented in this article, conducted the analysis and interpretation of data and drafted the article; SO approved version to be published.

Provenance and peer review Not commissioned; externally peer reviewed

\section{REFERENCES}

1. Lown EA, Vega WA. Intimate partner violence and health: self-assessed health, chronic health, and somatic symptoms among Mexican American women. Psychosom Med 2001;63:352-60.

2. Krug EG. World report on violence and health. Geneva: World Health Organization 2002:87-122.

3. Campbell J, Jones AS, Dienemann J, et al. Intimate partner violence and physical health consequences. Arch Intern Med 2002;162:1157-63.

4. Coker AL, Smith PH, Bethea L, et al. Physical health consequences of physical and psychological intimate partner violence. Arch Fam Med 2000:9:451-7.

5. Coker AL, Davis KE, Arias I, et al. Physical and mental health effects of intimate partner violence for men and women. Am J Prev Med 2002:23:260-8.

6. Pico-Alfonso MA, Linares-Garcia I, Navarro-Celda N, et al. The impact of physical, psychological, and sexual intimate male partner violence on women's mental health depressive symptoms, posttraumatic stress disorder, state anxiety, and suicide. $J$ Womens Health 2006;15:599-611.

7. Garcia Moreno C, Jansen H, Ellsberg M, et al. Prevalence of intimate partner violence: findings from the WHO multi-country study on women's health and domestic violence. Lancet 2006;368:1260-9.

8. Ellsberg M, Heise L. Researching violence against women: a practical guide for researchers and activists. Washington DC, United States: World Health Organization PATH, 2005.

9. Heise L, Ellsberg M, Gottemoeller M. Ending violence against women. Popul Rep 1999;27:1-43.

10. Morrison A, Ellsberg M, Bott S. Addressing gender-based violence: a critical review of interventions. World Bank Res Obs 2007;22:25-51.

11. Walton-Moss B, Manganello J, Frye V, et al. Risk factors for intimate partner violence and associated injury among urban women. $J$ Community Health 2005:30:377-89

12. Foa EB, Cascardi M, Zoellner LA, et al. Psychological and environmental factors associated with partner violence. Trauma Violence Abuse 2000;1:67-91.

13. Jewkes R, Levin J, Penn-Kekana L. Risk factors for domestic violence: findings from a South African cross-sectional study. Soc Sci Med 2002;55:1603-17.

14. Rodriguez E, Lasch KE, Chandra $\mathrm{P}$, et al. Family violence, employment status, welfare benefits, and alcohol drinking in the United States: what is the relation? $J$ Epidemiol Community Health 2001;55:172-8.

15. Gil-Gonzalez D, Vives-Cases C, Alvarez-Dardet C, et al. Alcohol and intimate partner violence: do we have enough information to act? Eur J Public Health 2006:16:278-84.

16. Kyriacou DN, Anglin D, Taliaferro E, et al. Risk factors for injury to women from domestic violence. N Engl J Med 1999;341:1892-8. 
17. Gil-Gonzalez D, Vives-Cases C, Ruiz MT, et al. Childhood experiences of violence in perpetrators as a risk factor of intimate partner violence: a systematic review. J Public Health (Oxf) 2008;30:14-22.

18. Peedicayil A, Sadowski LS, Jeyaseelan L, et al. Spousal physical violence against women during pregnancy. BJOG 2004;111:682-7.

19. Raj A, Santana MC, La Marche A, et al. Perpetration of intimate partner violence associated with sexual risk behaviors among young adult men. Am J Public Health 2006;96:1873-8.

20. Hotaling GT, Sugarman DB. An analysis of risk markers in husband to wife violence: the current state of knowledge. Violence Vict 1986;1:101-24.

21. Hotaling GT, Sugarman DB. A risk marker analysis of assaulted wives. J Fam Violence 1990:5:1-13

22. Stith S, Green N, Smith D, et al. Marital satisfaction and marital discord as risk markers for intimate partner violence: a meta-analytic review. J Fam Violence 2008:23:149-60

23. Bassuk E, Dawson R, Hungtington N. Intimate partner violence in extremely poor women: longitudinal patterns and risk markers. J Fam Violence 2006:21:387-99.

24. Carlson BE, McNutt L-A, Choi DY, et al. Intimate partner abuse and mental health: the role of social support and other protective factors. Violence Against Women 2002;8:720-45.

25. Zlotnick C, Johnson DM, Kohn R. Intimate partner violence and long-term psychosocial functioning in a national sample of American women. $J$ Interpers Violence 2006;21:262-75.

26. Coker AL, Watkins KW, Smith PH, et al. Social support reduces the impact of partner violence on health: application of structural equation models. Prev Med 2003;37:259-67.

27. Lynch SM, Graham-Bermann SA. Woman abuse and self-affirmation: influences on women's self-esteem. Violence Against Women 2000;6:178-97.

28. Sorenson SB. Violence against women: examining ethnic differences and commonalities. Eval Rev 1996;2:123-45.

29. Concha-Eastman A. Violence: a challenge for public health and for all. J Epidemiol Community Health 2001;55:597-9.

30. Gracia E, Herrero J. Acceptability of domestic violence against women in the European Union: a multilevel analysis. J Epidemiol Community Health 2006:60:123-9.

31. Tabassum Naved R, Åke Persson L. Factors associated with spousal physical violence against women in Bangladesh. Stud Fam Plann 2005;36:289-300.

32. Babcock JC, Waltz J, Jacobson NS, et al. Power and violence: the relation between communication patterns, power discrepancies, and domestic violence. J Consult Clin Psychol 1993:61:40-50.
33. Nikolic Ristanovic V. Domestic violence. In: Nikolic Ristanovic V, ed. Social change, gender and violence: post-communist and war affected societies. Dordrecht/ Boston/London: Kluwer Academic Publishers, 2002:75-104.

34. Watts C, Heise L, Ellsberg M, et al. Putting women first: ethical and safety recommendations for research on domestic violence against women. Geneva: World Health Organization, 2001, Document No. WHO/EIP/GPE/01.1.

35. Otašević S. Nasilje u partnerskim odnosima i zdravlje. Beograd: Autonomni ženski centar, 2005

36. Strauss $\mathbf{M}$, Hamby $\mathrm{S}$, Boney-McCoy $\mathrm{S}$, et al. The revised conflict tactics scales (CTS2). J Fam Issues 1996;17:283-316.

37. World Health Organization. WHO multi-country study on women's health and domestic violence: study protocol. Geneva, Switzerland: World Health Organization, 2004.

38. Kishor S, Johnson K. Risk factors for the experience of domestic violence. Profiling domestic violence: a multi-country study. Calverton, Maryland: Measure DHS + ORC Macro, 2004:27-52.

39. Vyas S, Kumaranayake L. Constructing socio-economic status indices: how to use principal components analysis. Health Policy Plan 2006;21:459-68.

40. Nikolić Ristanović V. Porodično nasilje u Srbiji. Beograd: Viktimološko društvo Srbije i Prometej, 2002.

41. Ruiz-Perez I, Plazaola-Castano J, Vives-Cases C. Methodological issues in the study of violence against women. J Epidemiol Community Health 2007;61:ii26-31.

42. Jansen HAFM, Watts $C$, Ellsberg $M$, et al. Interviewer training in the WHO Multicountry study on women's health and domestic violence. Violence Against Women 2004;10:831-49.

43. Kim J, Gray KA. Leave or stay? Battered women's decision after intimate partner violence. J Interpers Violence 2008;23:1465-82.

44. d'Oliveira AFPL, Schraiber LB, Franca IJ et al. Factors associated with intimate partner violence against Brazilian women. Rev Saude Publica 2009;43:299-311.

45. Vung N, Ostergren P-0, Krantz G. Intimate partner violence against women in rural Vietnam-different socio-demographic factors are associated with different forms of violence: need for new intervention guidelines? BMC Public Health 2008;8:55.

46. Orava TA, McLeod PJ, Sharpe D. Perceptions of control, depressive symptomatology, and self-esteem of women in transition from abusive relationships. J Fam Violence 1996:11:167-86.

47. Brownridge DA, Halli SS. "Living in sin" and sinful living: toward filling a gap in the explanation of violence against women. Aggress Violent Behav $2000 \cdot 5 \cdot 565-83$. 